\title{
O SANGUE NOSSO DE CADA DIA: VIOLÊNCIA E APROPRIAÇÃO NARRATIVA NA LITERATURA DE DALTON TREVISAN
}

Rodrigo Gomes de Araujo ${ }^{61 *}$

RESUMO: Analisa-se o livro Pão e sangue, de 1988, do escritor Dalton Trevisan, estuda-se a violência narrada pelo autor. São discutidas também as apropriações que o autor faz da mídia informativa. Dalton extrai das informações recebidas, aspectos que julga serem interessantes e transforma-os em literatura. Assim, transmuta notícias maniqueístas em histórias mais próximas do leitor. Pão e sangue está relacionado com a década de 1980, período em que a violência aumentou consideravelmente no Brasil. Suas histórias são construídas a partir das observações de um contexto de violência banalizada. Apesar de haver uma mentalidade de que o lar é um local desvinculado de atitudes violentas, isto é uma construção que deve ser repensada.

Palavras-chave: História Literária, Dalton Trevisan, violência, apropriação narrativa.

\section{A trajetória do autor}

Dalton é avesso a fãs e entrevistas e evita aa máximo as especulações e o público. Quase nada se sabe a respeito de sua vida privada. Duas de suas frases chavões são "O autor não vale o personagem, só a obra interessa. O conto é sempre melhor que o contista.".

Em 1946, Dalton faz sua estréia em âmbito nacional ao publicar a revista Joaquim juntamente com artistas e intelectuais como Wilson Martins, Erasmo Pilotto, Poty Lazarotto, Guido Viaro, dentre vários outros. A revista possui grande importância, e é responsável por revelar a literatura de Curitiba ao resto do país. Com um projeto de modernização literária, Joaquim apresenta-se iconoclasta ao criticar o movimento modernista, que para os idealizadores da revista já está ultrapassado em 1946 (SIMÕES: 1983, 21-22).

O escritor rejeita as obras produzidas antes de Novelas nada exemplares, de 1959, seu primeiro livro comercializado. Desde então é alvo de críticas das mais variadas. Suas obras são bastante populares e a maioria já passou por várias reedições. Em sua busca pela síntese, Dalton reescreve suas histórias a fim de torná-las mais concisas, e narra somente o essencial para que o próprio leitor construa sua interpretação de cada uma. Sua narrativa aproxima-se do discurso jornalístico - quase exclusivamente factual - e juntamente com as revisões de sua obra, apresentam diversos pontos de vista de uma mesma história. São exemplos marcantes disto as histórias produzidas com estrutura de depoimentos, da vítima e do criminoso, geralmente divergentes. Cabe ao leitor interpretar a narrativa 61 Graduando do 8 período de História pela Universidade Federal do Paraná (UFPR). Orientado pelo Prof. ${ }^{\circ}$ Dr. Renato Lopes Leite. Vinculado ao grupo de estudos "História Intelectual, História dos Intelectuais e Historiografia - UFPR".

Plataforma lattes: http://dgp.cnpq.br/buscaoperacional/detalheest.jsp?est=1420000308882220 
e estabelecer um juízo sobre o caso (WALDMAN: 1982, 25). Devido à sua "obsessão" em reescrever suas histórias, Dalton recebeu várias vezes a pecha de "autor do mesmo tema", "repetitivo", "autor somente da guerra conjugal".

Das interpretações da obra de Dalton, praticamente todas tratam em algum momento da repetição e auto-revisões que o autor realiza. As interpretações chamam a atenção para apropriação da imprensa periódica, bem como a representação da violência domiciliar. Os estudos foram realizados nas áreas de Letras ou Jornalismo, e há a importância de se estudar o escritor inserido no contexto curitibano (BERNARDI: 1983, 3-4), principalmente, sob o viés histórico. Uma vez que sua literatura está marcada por um período de grandes mudanças ocorridas a partir da década de 1960, e é uma das bases de sua narrativa e crítica. $O$ autor deixa transparecer o quanto estas mudanças influenciam as atitudes e histórias de seus personagens. A violência, narrada pela mídia informativa, é apropriada pelo autor, que a transfere às suas histórias, e transforma ditos "fatos reais" em narrativa literária.

\section{Pão, sangue, jornal}

"Toda noite ele sai do serviço, passa no boteco, chega bêbado em casa. Na pobre de mim se vinga do patrão e do preço das coisas. Doze anos casada, são dez que qualquer motivo apanho". Assim Dalton inicia Pão e sangue, que logo nas três primeiras frases diz a que vem. Publicado em 1988, o livro apresenta seu foco pautado na violência, principalmente doméstica - física e psicológica ${ }^{62}$ Segundo várias interpretaçõęs o curitibano se apropria da comunicação de massa - através de jornais, revistas, rádio, TV -, para buscar iṇspiração para sua produção literária. Mas Dalton não se restringe a absorver a inspiração, apropria-se também do estilo narrativo.

Pelo próprio título da obra podemos perceber a apropriação feita pelo autor. Pão e sangue é uma referência à idéia de governo romana, pão e circo (SANCHES NETO: 1996, 118). Nesta idéia está subjacente a espetacularização da violência, pois segundo tal idéia os espetáculos de violência eram associados ao assistencialismo, para desviar o olhar público de problemas de maior ordem social. Logo, aparecem já no título a apropriação e uma crítica à imprensa informativa, pois a mídia, neste sentido, estaria desviando o olhar público dos problemas sociais. Deste modo pode-se entender que a expressão Pão e sangue é uma referência ao fascínio que "casos de assassinatos, roubos e perversões exercem sobre a população, fazendo dos programas policiais e dos jornais vermelhos um sucesso de público" (SANCHES NETO: 1996, 118). À expressão Pão e sangue pode-se ainda atribuir outro sentido, o autor coloca lado a lado atitudes simples e cotidianas (pão) com a violência (sangue). Assim, já no título, Dalton transmite a idéia de que as atitudes violentas de seus personagens são comuns, esta brutalidade acontece normalmente e está tão presente na rotina quanto um pão.

Violência física é entendida aqui no sentido de Violência em ato: intervenção física voluntária que tenha por finalidade causar dano a outro, ou a si mesmo. Já a violência psicológica, entendida como ameaça de violência: consiste em obrigar o outro a manter condutas que este não deseja. É uma forma de violência coercitiva que pode resultar na violência em ato, sob a forma de punição ou advertência (STOPPINO: 1991, 1291-1293). 
Na obra, Dalton dialoga com os meios de comunicação de massa, seja aos buscar neles sua temática central, seja valendo-se de sua forma narrativa. O curitibano se apropria da estrutura dos depoimentos, e oferece ao leitor mais de uma versão do mesmo fato. Por exemplo, em "Você me paga, bandido" a história é narrada em duas versões em primeira pessoa. Maria nos diz que é casada há dez anos, seu marido é um alcoólatra e sempre que bebe a ameaça com o revólver. Na festa de casamento de uma amiga do casal, o marido ficou se insinuando com uma estranha. Quando João, o marido, tentou ir embora sem a esposa, ela, enciumada, atirou um caneco de chope no pára-brisa do carro. Depois do casamento, João foi ao clube, sem deixar dinheiro para que Maria fizesse as compras da casa. A esposa foi atrás dele no clube, ele se negou a the dar dinheiro. Maria perdeu a paciência, tirou um revólver da bolsa e atirou em direção ao marido, sem intenção de acertar, porém acertou-Ihe um tiro na perna. Ao final da história, ela declara que João já está bem, e quando não bebe é carinhoso com ela. Já na versão contada por João, sua esposa gasta muito dinheiro. Ele a conheceu quando Maria trabalhava em uma boate, casaram-se e tiveram filhos. No casamento da amiga, Maria estava bêbada, por isso ele conversava com a esposa de um amigo. João foi ao clube, sua esposa chegou depois, ainda embriagada, pedindo dinheiro, ele se negou a dar. Maria atirou contra ele e acertou-Ihe a perna. Esta não foi a primeira vez que a esposa Ihe deu um tiro, isto já havia ocorrido antes de casarem. João termina, justificando que "Se quisesse matar, de tão perto ela não tinha errado" (TREVISAN: 1988, 33). E diz que já a perdoou.

Nesta história podemos perceber que o escritor se vale da estrutura narrativa do depoimento. Deste modo, Dalton se apropria da imprensa informativa de forma velada. $\mathrm{O}$ autor entra em contato com as notícias de jornal, as desconstrói, e torna a construí-las de forma relativizada. Assim, oferece ao leitor não uma narrativa maniqueísta, na qual se atribuiria a culpa a um dos envolvidos, pois os personagens do contista não são vítimas ou vilões, são pessoas simples que buscam viver suas vidas. Ambos explicam a história de modo a atribuir a culpa ao "outro". Maria nos diz que o marido é um alcoólatra e sempre a ameaça. A esposa declara, "De briga não sou" (TREVISAN: 1988, 29), enquanto o marido pouco se importa com família e gasta seu salário em diversões particulares, possivelmente com outras mulheres. Já João, narra que sua esposa é uma ex-prostituta, e já tentou matá-lo anteriormente. É interessante que ao final ambos declaram já terem desconsiderado o ocorrido e estarem vivendo bem. Nota-se com isto a banalização da violência.

Há passagens da história que deixam transparecer, por um lado, o quanto a violência é rotineira e normal aos personagens, e também, o quanto ela está associada ao "outro". Na narrativa de Maria, ela indaga que o marido "Nem pensou no meu filho internado no asilo?" (TREVISAN: 1988, 30). Enquanto na de João, percebe-se que quando casaram Maria "Já tinha um menino, doidinho, escondido no porão" (TREVISAN: 1988, 31). Associando os dois depoimentos pode-se notar que antes do casamento, Maria já possuía um filho com deficiências mentais. Através da indagação da esposa, percebemos que ela reclama de João parecer não se importar com o garoto. Já pelo depoimento de João, era ela mesma que prendia o filho no porão, antes do casamento. Outro trecho que evidencia a associação da violência ao "outro" é quando narram sobre o chope atirado no pára-brisa do carro. 
Maria diz "Não resisti e atirei o canequinho no pára-brisa. Sem força, molhou o vidro, só um nadinha" (TREVISAN: 1988, 30). Enquanto para João, a esposa "veio correndo e atirou o canecão no pára-brisa" (TREVISAN: 1988, 32). Quando ela conta a história, é um simples canequinho, e somente molha o vidro, sem força. Já quando é João quem conta, trata-se de um canecão, atirado depois que esposa veio correndo, ou seja, foi jogado de forma violenta. E ao final de ambas as narrativas, os personagens tecem elogios um ao outro, o que mostra que apesar de terem prestado depoimento sobre um ato de grande violência - os tiros proferidos contra João -, já desconsideram o ocorrido, pois para eles isto é natural.

Apesar de a apropriação da imprensa periódica não aparecer de forma explícita, ela aparece indiretamente em Pão e sangue. Entretanto há uma história produzida pelo escritor no início de sua carreira chamada "Notícia de jornal", publicada em 1946, na revista Joaquim. Nesta história, Dalton mescla a narrativa jornalística - factual e objetiva - com a narrativa lírica e poética. O próprio autor destaca que são usadas narrativas diferentes, pois apresenta o texto com grifos nos trechos referentes ao estilo de jornal. Vale citar algumas passagens que sintetizam a história:

Ontem, às 4 horas da tarde, na Praça do Patriarca, desenrolou-se rápida cena de sangue, em que um caixeiro, fazendo uso de seu revólver, assassinou a antiga amásia ( ) Raimundo, sério agora e calmo, fez um gesto de ir-se embora; a sua presença era-lhe dolorosa como uma nota de música vibrando aguda através um longo salão silencioso. Adeus, amor () sentiu que tinha muita pena de morrer. Se ele pudesse viver um dia mais, gozar o sol, olhar as estrelas, ouvir música, beber um chope () em seguida, voltou a arma contra si, sendo que () o projétil alojou-se-lhe certeiro no cérebro e ele caiu sobre si, ao lado do outro cadáver () A Polícia procedeu a remoção dos corpos para o necrotério, sendo que serão sepultados no Cemitério Municipal. Foi aberto inquérito. (TREVISAN: $1946,10-12$, grifos no original).

A presença do estilo narrativo da imprensa periódica é nítida nesta história, também o estilo lírico. É facilmente perceptivel que a parte grifada por Dalton refere-se a uma notícia - hipotética ou verdadeira -, enquanto os trechos sem grifos tratam-se de sua narrativa lírica. A diferença nas configurações de "Notícia de jornal" e "Você me paga, bandido" está exatamente no quanto o escritor deixa transparecer a apropriação realizada. Enquanto na primeira o estilo jornalístico aparece explícito a qualquer leitor, na segunda apropriação é camuflada através da desconstrução da notícia. Vale lembrar que Dalton atuou como repórter policial no início de sua carreira (TÁVORA: 1968, 13), assim, suas primeiras experiências profissionais influenciam em grande parte de sua produção literária.

Segundo Roger Chartier o conceito de apropriação pode ser entendido como tomar para si, como se fosse seu. São os diferentes usos, as diferentes compreensõés, juntamente com a liberdade de criação, dentro de práticas sociais específicas de cada sociedade. Para Chartier, qualquer tipo de categoria é variante para diferentes comunidades. A construção do sentido que se atribui ao mundo é feita pela apropriação das coisas. Neste sentido, apropriação é que gera a representação. Esta que pode ser entendida como tornar presente aquilo que está ausente. Ou seja, um modo se imaginar algo que não se mostra presente. Assim o texto literário surge como uma representação que permite ao leitor vislumbrar mentalmente uma ambientação, em qual não está no momento. O conceito de 
representação são as diferentes construções da realidade, modos específicos de se perceber o mundo, feitos por cada comunidade. Para o historiador, a identidade social é resultado da apropriação que a comunidade faz das representações impostas. Ou seja, a identidade social é fruto dos diferentes usos que se dão às representações. Assim, o conceito de representação proposto por Chartier une as categorias mentais, às trajetórias e práticas sociais.

Deste modo, ao se apropriar da narrativa oral do depoimento, Dalton está representando uma ambientação, nas acepções de representação propostas por Chartier. Pois para que os textos de Dalton tornem-se plenos de sentido é necessário que leitor imagine o que lhe é narrado, e crie uma imagem mental da história, ou seja, uma representação. Mas, além disto, é preciso que o leitor destas narrativas orais seja o interlocutor dos personagens, e algumas vezes até mesmo imagine-se inserido na história. Por exemplo, em "Você me paga, bandido", o leitor deve imaginar ser o próprio interrogador do depoimento, pois os personagens fazem suas narrativas direcionadas a um "doutor" implícito, que é exatamente aquele que ouve - ou, neste caso, lê- - suas declarações. Deste modo, os leitores de Dalton devem criar uma representação na qual eles próprios estão inseridos, e também representam um papel. Caso contrário, os textos do escritor não podem ser plenamente compreendidos.

Em "Pão e sangue", história que nomeia o livro, fica clara a intenção de Dalton de demonstrar o eixo desejado para a obra. É a violência banalizada, pautada em um cotidiano saturado da vida a dois. Casados há dezessete anos, o casal vive uma constante guerra conjugal há cerca de um ano. Como na história anteriormente apresentada, o marido chega alcoolizado em casa e começa a discutir violentamente com a esposa, Maria, simplesmente porque ela não quer lavar sua camisa e também porque os filhos já o comeram todo o pão. Maria o desafia e João lhe desfere um soco, que é retribuído com uma estocada de vassoura. Ele agarra uma faca que está sobre a mesa e persegue a esposa, que foge para a rua. O marido a alcança e friamente lhe "corta o pescoço e enfia no peito a faca, de baixo para cima." (TREVISAN: 1988,95$)$. Depois de esfaquear a esposa, João é atingido por uma pedra atirada por um de seus filhos que assistem ao desfecho da luta. Ao avançar contra a criança, João é linchado pelos vizinhos que estão na rua.

Nesta história a violência é apresentada como algo normal, é banalizada, é o grotesco cotidiano que Dalton costuma narrar. O relacionamento de João e Maria se tornou violento a tal ponto que os dois motivos, praticamente irrelevantes - Maria se recusar a lavar a camisa e a falta de pão - são suficientes para que João assassine a esposa com quem vive há dezessete anos. Na narrativa aparecem várias evidências de que os protagonistas estavam acostumados a essa rotina de brutalidade e degradação: Maria "dorme com um punhalzinho debaixo do travesseiro" para se defender do marido que dorme ao seu lado. "João sai do trabalho [e toda noite], passa no boteco, quem não toma uns aperitivos?" (TREVISAN: 1988, 93). Para Maria, é natural ter que se preocupar em se defender do marido. Enquanto para João, é comum se embriagar todas as noites, tanto que se entende que sua atitude é algo aceito socialmente, este é o sentido da pergunta "quem não toma uns aperitivos?". Também a faca com que ele assassina a esposa, antes de ser uma arma, é uma utilidade doméstica, pois está sobre a mesa. 
Segundo Monika Jakubowska, "Pode-se dizer que Dalton Trevisan escreve um único livro, no qual relata a decadência da vida familiar e a degradação da convivência entre pessoas" (JAKUBOWSKA: 1980 , 2). Através da observação da autora é possível entender então que os laços afetivos não estão presentes na literatura do curitibano, pois em sua obra a convivência não cria laços, mas sim decadência e degradação.

Na história "Pão e sangue", os personagens já estão saturados um com o outro, tanto que qualquer pretexto se torna suficiente para que a violência psicológica torne-se física. Dalton representa de forma concisa essa degradação em um micro-conto, apresento-o integralmente: "Em toda casa de Curitiba, João e Maria se crucificam aos beijos na mesma cruz." (TREVISAN: 1994, 136). Os personagens de Dalton convivem juntos, torturam-se mutuamente, crucificam-se na cruz que é a vida a dois. Em sua metáfora pode-se entender que matam um ao outro aos poucos, sangram de forma conotativa através da violência psicológica, até que a rotina se torne insustentável, e por meio da violência física sangrem-se literalmente, até a morte.

\section{O livro e o contexto}

Neste ponto da análise, se faz necessário contextualizar o livro estudado, e como já exposto, Pão e sangue tem sua publicação no ano de 1988. Logo, é preciso que se pense o contexto brasileiro durante esta década. Segundo Alba Zaluar, a violência no Brasil aumentou consideravelmente neste período. O tema passou a ser um dos principais alvos do debate público e da imprensa. Com isto a violência se torna cotidiana, deixa de ser estranha e torna-se natural. A mídia tem um papel fundamental na banalização da violência, pois ela muitas vezes "distorce a informação e confunde mais que esclarece. As notícias de violência tornaram-se mercadorias. Elas vendem bem o veículo, quanto mais sensacionalistas e impactantes forem" (ZALUAR: 1998, 247).

As proposições da autora nos revelam que a literatura em questão está associada a uma conjuntura de mudanças no país, pois a violência aumenta nas áreas urbanas brasileiras durante as décadas de 1980 e 1990, principalmente em regiões metropolitanas. Especificamente, no caso de Curitiba as estatísticas do IPPUC (Instituto de Pesquisa e Planejamento Urbano de Curitiba) mostram que o total de crimes praticados na cidade em 1986 é de 16.288 , sobe para 23.380 em 1987, e atinge 23.814 em 1988 (IPPUC: 2001). Ou seja, a criminalidade na grande Curitiba apresenta um aumento de $46 \%$ em apenas três anos.

Se pensarmos a literatura de Dalton sob estas proposições, pode-se dizer que seus personagens são influenciados pelo contexto de violência banalizada - pela mídia e por eles próprios -. Suas ações são naturalmente violentas, mas associam a violência ao "outro" e não conseguem perceber que esta brutalidade cotidiana está em cada um deles. Zaluar também chama a atenção para esta tendência a se atribuir a violência ao "outro", o fenômeno é entendido geralmente como estando distante, e apesar de ser percebido como algo cotidiano, o próprio espectador não aceita que esteja próximo a 
ele, assim a violência é negada (ZALUAR: 1998, 248).

Para Zaluar a violência brasileira pós década de 1980 não pode ser entendida como uma continuidade - pois não era tão evidente antes, e acentua-se na década de 1980 -, nem deve ser pensada como uma conseqüência direta da miséria e do excesso populacional, uma vez que estes estão presentes na realidade brasileira desde os anos 1950. As causas do fenômeno, segundo a autora, estão também relacionadas ao comportamento diante da revolução sexual, tendo em vista que a partir dela os laços matrimoniáis afrouxaram, e diminuiu também a responsabilidade paterna. A liberdade sexual se tornou mais importante do que criar adequadamente os filhos, tal função ficou sob responsabilidade da escola, que não estava preparada para assumir as funções que anteriormente eram da família.

Neste sentido, vale lembrar os personagens de "Você me paga, bandido". Maria, que prende o próprio filho no porão, e também João que gasta seu dinheiro com diversões particulares e deixa a família de lado. Nota-se nos personagens que não há nenhuma responsabilidade com relação à família, estão preocupados com sua própria individualidade.

Zaluar ainda observa que no Brasil, a grande inflação que abalou o país desde o início do regime democrático até o advento do Plano Real, em 1994, contribuiu para a conjuntura de violência. Pois, para a autora, a inflação foi mais que um fator econômico, gerou também comportamentos criminosos e violentos, principalmente entre aqueles que viviam de salários mínimos, pois não havia confiança mútua entre agentes econômicos, isto abalava as relações sociais. Por um lado, isto ocorreu na esfera pública, na medida em que se buscavam meios de contornar a crise através de empregos informais e criminosos, sob o ideal de "dinheiro fácil". Surgem, por exemplo, neste período muitas quadrilhas de crime organizado. Já na esfera privada, o comportamento, apesar de ficar camuflado pelos silêncios da vida doméstica, também foi acentuadamente violento, e a autora explica que, foram decorrentes de novos padrões comportamentais, baseados na desestruturação familiar.

Pão e sangue pode então ser entendido como uma obra que tem o intuito de desvendar estes silêncios da violência doméstica. Estes silêncios da brutalidade cotidiana surgem na obra de uma forma explícita na história "Hoje é o dia", pois há uma passagem em que Maria recebe algumas pancadas do marido, e declara, "- Ai João. Olhe as crianças. Na frente delas, não" (TREVISAN: 1994, 44). Percebe-se que Maria queria esconder até mesmo dos filhos, a violência que sofria. É interessante também destacar que o estilo narrativo desta história é o da conversa íntima, como se Maria estivesse conversando um amigo, que no caso deve representado pelo próprio leitor. Ou seja, não é um depoimento, que tornaria a história pública, é antes uma conversa íntima. Assim, podemos perceber que Maria não tem a intenção de revelar a brutalidade do marido, está até mesmo acostumada a ela, uma vez que não pede ao marido para que não bata nela, mas sim que não bata em frente aos filhos.

Mesmo a imprensa periódica revela está violência domiciliar, antes de Dalton, a grande maioria dos casos é omitida pelos envolvidos, e mesmo quando divulgados por jornais, a informação sobre os atos de brutalidade fica restrita aos limites da cidade. Uma vez publicados por Dalton, podem chegar 
a leitores de várias partes do mundo, lembrando que o escritor é lido em muitos idiomas.

Através da literatura de Dalton é possível que se reveja está idéia de que o espaço privado está isento de qualquer tipo de violência, uma vez que em Pão e sangue a maior parte dos atos de brutalidade ocorre dentro de casa, e é realizado pelos familiares. Sua obra pode ser pensada, assim, como uma denúncia de que a violência não está somente lá fora, no espaço público, mas também dentro das casas, é tão cotidiana que chega a ser banalizada e passa despercebida.

\section{Roupa suja se lava em casa}

Ao se apropriar da imprensa periódica, Dalton não o faz unilateralmente em Pão e sangue. O autor estabelece contato com a mídia informativa, da qual retira boa parte dos temas de suas narrativas. Mas, na obra em questão não coincidem o estilo narrativo jornalístico com histórias tematizadas pela violência domiciliar. Não restam dúvidas de que o escritor recorre aos meios de comunicação para criar sua literatura. Dalton entra em contato com a impressa informativa, observa narrativas quase exclusivamente factuais e maniqueístas, e desconstrói as notícias, para posteriormente remontá-las em forma de literatura com caráter artístico. As notícias, uma vez assimiladas pelo escritor tornamse relativizadas. Assim, por exemplo, uma notícia que narra o assassinato de um homem por sua esposa, pode ser reapresentada pelo autor como um caso em que o marido costumava espancá-la, isto ameniza, mas não retira a culpa da esposa criminosa.

Assim, Dalton "reconstrói" um contexto observado, e imagina possíveis motivos e antecedentes para as informações por ele recebidas. Cria a partir das informações a que tem acesso um enredo contextualmente possível, no qual geralmente cabe ao leitor estabelecer o juízo. O contista tenta permanecer neutro, no sentido em que não aponta a culpados, criminosos ou vítimas. Em sua cidade transposta para a literatura não há bons ou maus, os personagens vivem e cometem atrocidades, sem se darem conta disto. A violência é rotineira e normal para eles, e também está associada ao "outro". Seus personagens estão acostumados a um cotidiano de brutalidade e degradação.

O livro está diretamente ligado a um contexto de mudanças no país - notadamente a década de 1980 -, no qual os índices de violência aumentaram consideravelmente, principalmente nas áreas urbanas e metropolitanas, que, não por acaso, são os principais cenários das narrativas de Dalton. Seus personagens e histórias são construídos a partir das observações de um contexto de violência banalizada - pela mídia e por eles próprios -. Apesar da imprensa jornalística, de certa forma, denunciar o crescimento da violência domiciliar no período abordado, a tendência é que os crimes sejam apresentados de forma maniqueísta. Já na obra do escritor, não há culpados, pois a brutalidade está latente nas pessoas, e basta que vivam em um ambiente saturado de pequenas violências psicológicas para que a expressem de forma física.

Apesar de haver uma mentalidade de que o lar é um local desvinculado de atitudes violentas, isto é uma construção que deve ser repensada. Pois a brutalidade doméstica é, na maioria das vezes, 
camuflada, e uma vez que é pouco exposta ao olhar público, surge a idéia de que não existe, ou existe em menor número. Deste modo, Pão e sangue pode ser interpretado como uma denúncia de que a violência se faz presente também na vida privada. Neste sentido, o livro é uma crítica social e tem o intuito de fazer com que os leitores questionem até que ponto esta violência, narrada por Dalton, configura-se como uma realidade social. Se em Pão e sangue, o escritor realiza uma denúncia da brutalidade cotidiana, em Måcho não ganha flor, uma de suas mais recentes publicações, de 2006, 0 autor volta sua temática aos estupros, o que torna possível a indagação de em que medida este livro representa um novo contexto, e até ponto é uma simples mudança temática de Dalton.

\section{Referências}

BERNARDI, Rosse Marie. Dalton Trevisan: A trajetória de um escritor que se revê. São Paulo, 1983. Tese (doutoramento) Universidade de São Paulo.

CHARTIER, Roger. "O mundo como representação". In: Estudos avançados, no. 11, v. 5, 1991.

CHARTIER, Roger. A ordem dos livros: leitores, autores e bibliotecas na Europa entre os séculos XIV e XVIII. Brasilia: Editora da UnB, 1994.

GINZBURG, Carlo. Nenhuma ilha é uma ilha: Quatro visões da literatura inglesa. São Paulo: Cia. das Letras, 2004.

GINZBURG, Carlo. Mitos, emblemas, sinais: morfologia e história. São Paulo: Cia. das Letras, 1989.

GOMES, Álvaro Cardoso; VECHI, Carlos Alberto. Dalton Trevisan. São Paulo: Abril Cultural, 1981.

GRANATO, Fernando. "Dalton Trevisan" In: Esses jovens escritores. Curitiba: Fundação Jacob Ditzchman, 1989.

JAKUBOWSKA, Monika. "Posfácio; Dalton Trevisan". Documentação Paranaense, BPP, 1980.

NICOLATO, Roberto. Literatura e Cidade: o universo urbano em Dalton Trevisan. Curitiba, 2002. Dissertação (mestrado). UFPR.

PAES, José Paulo. "Uma voz na Babilônia", "A guerra sexual". In A Aventura Literária: ensaios sobre ficção e ficções. São Paulo: Cia. das Letras, 1990.

PRINCIPAIS CRIMES PRATICADOS EM CURITIBA: 2001 desde 1986. Instituto de Pesquisa e Planejamento Urbano de Curitiba (IPPUC). Curitiba, 2001. In: http://ippucnet.ippuc.org.br/Bancodedados/Curitibaemdados/ Curitiba_em_dados_Pesquisa.asp. Acessado em 19/04/2008.

RÜSEN, Jörn. Razão Histórica - Teoria da História: os fundamentos da ciência Histórica. Brasília: Editora da UnB, 2001.

SANCHES NETO, Miguel. O artifício obsceno: visitando a polaquinha. Ponta Grossa: Centro de 
Publicações, 1994.

SANCHES NETO, Miguel. Biblioteca Trevisan. Curitiba: Editora da UFPR, 1996.

SIMÕES, João Manuel. Alguns estudos breves sobre Dalton Trevisan. Curitiba: Litero-Técnica, 1993. STOPPINO, Mario. "Violência". In: BOBBIO, Norberto. Dicionário de política. Brasília: Linha Gráfica Editora, 1991.

TÁVORA, Araken. "Meu encontro com o vampiro". In: Panorama. Curitiba, 18 (191): 14 jul. 1968.

TREVISAN, Dalton. Abismo de rosas. Rio de Janeiro: Record, 1979.

Ah, é? Rio de Janeiro: Record, 1994.

Arara bêbada. Rio de Janeiro: Record, 2004.

Crimes da paixão. Rio de Janeiro: Record, 1978.

Desastres do amor. Rio de Janeiro: Record, 1993.

Em busca de Curitiba perdida. Rio de Janeiro: Record, 2002.

Essas malditas mulheres. Rio de Janeiro: Record, 1983.

Guerra conjugal. Rio de Janeiro: Record, 1995.

"Notícia de jornal". Joaquim. Curitiba, 2: junho de 1946.

Meu querido assassino. Rio de Janeiro: Record, 1988.

Novelas nada exemplares. Rio de Janeiro: Record, 1979.

Pão e sangue. Rio de Janeiro: Record, 1988.

O pássaro de cinco asas. Rio de Janeiro: Civilização Brasileira, 1974.

A Polaquinha. Rio de Janeiro: Record, 1985.

O vampiro de Curitiba. Rio de Janeiro: Record, 1998.

VERNIZI, Rosangela Nascimento. Erotismo e transgressão: a representação feminina em A Polaquinha de Dalton Trevisan. Curitiba, 2006. Dissertação (mestrado). UFPR.

VILASBOAS, Manoel dos Santos. Trevisan: revisão. Porto Alegre, 1977. Tese (doutoramento). PUCRS.

WALDMAN, Berta. Do vampiro ao cafajeste: uma leitura da obra de Dalton Trevisan. São Paulo: Secretaria da Cultura e do Esporte do Governo do Paraná, 1982.

ZALUAR, Alba. "Para não dizer que não falei de samba: os enigmas da violência no Brasil”. In: SCHWARCZ. Lilia Moritz (org.). História da vida privada no Brasil: contrastes da intimidade contemporânea (vol. 4). São Paulo: Companhia das Letras, 1998. 